ALPHA No 29 Diciembre 2009 (67-83)

ISSN 0716-4254

http://alpha.ulagos.cl

\title{
CARLOS FUENTES Y SU INCURSIÓN EN LA NARRATIVA POLICIAL
}

Carlos Fuentes and his attempts at detective stories

Jaime Alberto Galgani*

Resumen

La única obra de Carlos Fuentes perteneciente al género policial es La cabeza de la hidra (1978). Centrada en las problemáticas asociadas con el contrabando de petróleo hacia los Estados Unidos, durante la década de los 70, este relato se ubica en el contexto de la novela negra latinoamericana, presentando ciertos rasgos que la acercan al neopolicial. Con una notable hibridación de géneros, se presenta la parodia narrativa de un detective que viene a ser la versión invertida, latinoamericana, de James Bond. El artículo indaga en la novela para determinar la función que el género policial cumple en ella.

Palabras clave: Hibridación, neopolicial, novela negra latinoamericana, parodia.

Abstract

The only work by Carlos Fuentes belonging to the detective story genre is $L a$ cabeza de la hidra (1978). This story, which centers on problems relating to oil smuggling into the United States during the 70 s, is to be found within the contexts of the Latin-American black novel, presenting certain features which approximate the neo-detective narrative. With a remarkable hybridization of genres, the narrative parody of a detective is presented which happens to be the Latin-American opposite version of James Bond. The article analyses the novel with the purpose of determining the function that the neo-detective genre performs in it.

Key words: Hybridization, neo-detective, Latin-American black novel, parody.

La incursión de Carlos Fuentes en la novela policial es breve y, al parecer, poco apreciada por él mismo. En 1978 aparece La cabeza de la hidra que poca recepción tuvo en el ámbito literario y que fue concebida, tanto por Fuentes como por los críticos del momento, como un thriller de espionaje liviano a modo de una versión tercermundista de James Bond. A inicios de los ochenta, Paul Leduc intentó llevarla al cine, solicitando a Héctor Aguilar Camín que redactara el guión. Dedicado a la empresa encomendada, Aguilar Camín quizás fue uno de los primeros en rescatar las posibilidades del relato policial de Fuentes 
Jaime Alberto Galgani

Desarmando aquella caja de convenciones literarias, alusiones y enigmas autorreferenciales, entendí hasta qué punto la obra de Fuentes, aun la más inocente y fácil en apariencia, es un palimpsesto de símbolos, significados y discursos dispares, cruzados por la libertad inusitada de un escritor que experimenta y juega sin parar: una cabeza bullente, henchida por igual del mundo y de las letras, de la historia y de la literatura, lo mismo que del cómic, el cine, la moda, la música popular y, en general, el vasto utillaje de la sociedad de consumo. Conviven en su obra Balzac y Joyce, Nefertiti y Jean Harlow, Francisco de Goya y Dick Tracy, Benito Juárez y la Tongolele (en línea).

Después del descubrimiento de Aguilar Camín, el mismo Carlos Fuentes parece haber reconocido en La cabeza de la hidra más posibilidades de las que creía

Quizás fue un error. Estaba exhausto por Terra Nostra, por la embajada... Quise divertirme escribiendo una parodia del género de espionaje, la historia de un James Bond del subdesarrollo. A pesar de todo, se me coló una amarga reflexión sobre el cinismo de la política internacional. Héctor Aguilar Camín quiso adaptarla al cine y se encontró que no había nada sino artificio literario, invención ficticia. Por lo menos eso prueba esta novela: escribo para la literatura, no para el cine. Buenos o malos, mis libros no tienen existencia fuera de la literatura (“Autobiografía...”, en línea).

A partir de este encuentro con La cabeza de la hidra, Aguilar Camín pudo recuperar su propia lectura de Fuentes e iniciar un camino de comprensión diferente, notando cómo - tras su vasto trabajo narrativo- es posible entender que todos los caminos confluyen, se reabren y se comunican, conectándonos con un mundo narrativo de generosas proporciones.

La novela está ambientada en los años setenta y trata de cómo un triple agente (cuyo nombre verdadero nunca se revela al lector pero que se hace llamar, en distintos momentos, con los apodos de Timón de Atenas/Trevor/ Mann) organiza una pequeña agencia de espionaje con el fin de desbaratar los propósitos de burlar las leyes mexicanas con respecto a la explotación del crudo petrolero existente en el subsuelo azteca. En efecto, dada la ley de nacionalización del petróleo, existente desde 1938 (gobierno de Cárdenas) es imposible que empresas internacionales encuentren una vía legal para aprovecharse de las ingentes reservas mexicanas. Por este motivo, intereses estadounidenses, judíos y árabes, con la connivencia de políticos corruptos mexicanos, generan una red de contrabando por vía marítima, aprovechando las rutas existentes en el Golfo de México. El triple agente, considerado como un empresario nacionalista, solicita la ayuda de Félix Maldonado para realizar 


\section{Carlos Fuentes y su incursión en la narrativa policial}

la tarea de desbaratamiento de la red. Para eso le instala una habitación en el Hotel Hilton, le hace cambiar de personalidad, de nombre y de rostro y le encomienda tareas específicas, dictadas en forma parcial y enigmática. Una de ellas es la recuperación de un anillo en cuya perla se encuentra holográficamente descrito el mapa de las riquezas petroleras mexicanas. En el cumplimiento de la misión, Félix Maldonado va descubriendo una compleja maraña que no lo excluye ni a él ni a los personajes más cercanos (incluyendo al super agente que lo envía) de las innumerables e inagotables fuerzas del mal. La estructura de la novela está constituida por cuatro capítulos: "El huésped de sí mismo”, "El agente mexicano”, “Operación Guadalupe”, "La guerra de la hidra” y un Epílogo. Los tres primeros organizan la acción de forma cinematográfica y el último es el que explica los acontecimientos. El hecho de que sea una novela inspirada en el cine es evidente, pues el texto está dedicado a "Conrad Veidt, Sydney Greenstreet, Peter Lorre, y Claude Rains, en estricto orden de desaparición”. ${ }^{1}$ Además, parece ser que estuviera hecha para ser representada cinematográficamente; esto, por los múltiples encuadres, sucesiones de escenas, superposiciones de cuadros y diálogos que no admiten la presencia de un narrador heterodiegético y exigen la colaboración activa del lector en la construcción del relato. Finalmente, atendiendo a la estructura de la obra, es posible ver que, si bien el narrador actúa a modo shakesperiano al generar un drama, la trama novelesca del mismo se configura cinematográficamente. Así, tanto Timón/Trevor/Mann (TTM) como Félix aparecen representados en sus aficiones correspondientes (teatro y cine) y en el modo como se influyen recíprocamente. Por otro lado, la organización cinematográfica de los textos sirve a los propósitos de una novela detectivesca que supone una gran participación por parte del lector en la disolución de la trama (lector como detective).

El narrador es TTM, pero esto no se sabe sino hasta el cuarto capítulo, si bien algunas intervenciones anteriores comienzan a dar luces respecto a que no es un narrador heterodiegético el que está relatando la historia, cuestión que naturalmente se piensa desde el principio.

La novela termina reproduciendo el texto que está en las primeras páginas y que relata el desplazamiento de Félix en taxi. Sin embargo, al final, hace el mismo recorrido pero con su nuevo nombre (Diego Velásquez) clausurándose justo en el momento cuando “(e)l Señor Presidente estaba a unos cuantos metros...” (279). Esta repetición cíclica (un nuevo nombre, pero la misma situación) alude al carácter fatalista de la historia mexicana, a su prehispánica concepción del tiempo, a su incapacidad de progresar, al

\footnotetext{
${ }^{1}$ Carlos, Fuentes. La cabeza de la hidra. Ciudad de México: Joaquín Mortiz, S. A. 1985:9. Citaremos por esta edición.
} 


\section{Jaime Alberto Galgani}

inevitable fatum que condena a reproducir la misma tragedia del pasado. Según Gloria Durán, esta concepción fatalista conecta a Fuentes con Rulfo, Paz, Azuela, Asturias pero, también, con la tradición fatalista hispánica (Lope de Vega, Luis Vives). De este modo, la novedad de su propuesta narrativa descansa básicamente en los mecanismos literarios que emplea más que en el tema propuesto (Durán, 1980:193s).

En la mitología griega, la hidra de Lerna era un antiguo y cruel monstruo acuático con forma de serpiente policéfala y de aliento venenoso. Sus cabezas podían ser de cinco a cien o, incluso, cien mil según la tradición que la refiera, y se reproducían cada vez que se las cortaba. Heracles, con la astucia y la colaboración de su sobrino Yolao y sirviéndose de la misma sangre envenenada de la hidra, terminó con ella en uno de sus "doce trabajos". Este mito es el que da sentido al título a La cabeza de la hidra poniendo en contacto el relato con la tradición mitológica, con el fin de ofrecer una clave de interpretación general del texto que, aparentemente, no va más allá de la rudimentaria y evidente asociación con los poderes del mal y las múltiples redes tejidas en torno a los intereses políticos y económicos relacionados con la posesión y administración de las abundantes riquezas petroleras subyacentes en el suelo mexicano. El interés de los Estados Unidos por explotar los cien millones de barriles de crudo intactos se ve motivado, en primer lugar, por la aguda crisis petrolera mundial desde la guerra del Yom Kippur (1973) y por razones económicas diversas asociadas al aumento progresivo de la demanda de petróleo por sobre las posibilidades de la oferta existente hasta entonces $\mathrm{y}$, en segundo lugar, por la visión política estadounidense animada por la "doctrina Monroe" (1823) que daba carta blanca a los "americanos” para intervenir en los demás países del continente cada vez que los intereses del Norte se vieran comprometidos. A esto se suma la endémica limitación por parte de los países latinoamericanos para manejar sus riquezas, con el consecuente sentimiento de superioridad de los norteamericanos, pues ellos sí tienen experiencia en administración de recursos

Guárdese sus discursos patrióticos, Maldonado (dice Trevor). México no puede sustentarse eternamente sobre la reserva petrolera más formidable del hemisferio (...) Sólo queremos que se beneficie de ella. Por las buenas, de preferencia. (...) No sean tercos, Maldonado. Lo que se juega es mucho más grande que su pobre país corrupto, ahogado por la miseria, el desempleo, la inflación y la ineptitud. Vuelva a mirar hacia afuera [Houston]. Se lo exijo. Esto fue de ustedes. No les sirvió de nada. Mire en lo que se ha convertido sin ustedes (164).

La "hidra" de Fuentes está formada por las múltiples relaciones de poder establecidas entre personajes vinculados a la banca norteamericana con 


\section{Carlos Fuentes y su incursión en la narrativa policial}

capitales judíos (Nueva York) al petróleo árabe y sus manejos comerciales en Houston, y a los colaboracionistas mexicanos dispuestos a burlar el principio de la nacionalización del petróleo mexicano, generando redes corruptas en las que todo es posible (fraudes, engaños, falsificaciones, contrabando y asesinatos) con tal de crear una vía clandestina de traspaso físico del crudo mexicano a manos estadounidenses. La alusión al mito responde a las múltiples manifestaciones del "mal”, a su indestructibilidad, a su venalidad inmarcesible y a las difusas posibilidades del héroe novelesco para acabar con él. En este sentido, el relato de Fuentes, si bien cumple con las características de la novela policial latinoamericana de la década de los sesenta, en donde se polemiza con las instituciones modernas (en este caso, la industria petrolera mexicana y los sectores económicos asociados) también asume rasgos de la novela policial posmoderna, en donde ya no es posible identificar al culpable e, incluso, tener claro el crimen, además de incluir la figura esmirriada de un investigador desprovisto de los poderes del detective moderno, incapaz de restituir totalmente el orden e, incluso, comprometido o afectado en parte por la dialéctica del mal.

No obstante lo dicho sobre la hidra de Lerna, no es ese el mito que gobierna el desarrollo general de la obra. Al menos, según Gloria Durán "despite the mythological title, the most conspicuous myth is that of James Bond” (a pesar de su título mitológico, el mito más visible es el de James Bond" (1980:183). ${ }^{2}$ Señala Durán que conversando con Fuentes —antes de la publicación del libro - el novelista describió la obra como “a spy mystery thriller about a poor, third-world James Bond who has none of the gadgets available to his more affluent counterparts who work for the superpowers", "un thriller de misterio sobre un James Bond pobre y tercermundista que no posee ninguno de los recursos de que sí disponen sus contrapartes más comunes que sirven a las superpotencias (superpoderes)”. La apropiación del mito pop relacionado con James Bond fue visto, por las pocas críticas que el libro recibió, como una forma relajada - no demasiado seria- del thriller clásico. Es así como Anthony Burguess comentaba en el New York Times (enero de 1979) que "(p)erhaps the true distinction of the novel resides in its having forever dispensed with the possibilities of the spy thriller as a serious form”, "quizás la verdadera distinción de la novela reside en su total prescindencia de las posibilidades del thriller de espía en su factura más seria” (1979:11).

Esta lectura del trabajo de Fuentes permite observar la figura de Maldonado como una "parodia" de su contraparte inglesa. Las diferencias saltan a la vista: latinoamericano, con poco poder real, involucrado

\footnotetext{
${ }^{2}$ La presente traducción y las siguientes son mías.
} 
afectivamente, menos sujeto que objeto. La transición del personaje inglés no sólo se da en la esfera cultural (de lo europeo a lo latinoamericano) lo cual ya supone un salto significativo, sino en la esfera del paradigma textual modélico desde el cual James Bond y Maldonado son generados, es decir, desde la concepción moderna del detective-espía-agente (que corresponde a James Bond) a la visión posmoderna (que corresponde a Maldonado). Estos dos saltos complejizan, además, la evaluación del texto por la consideración que podemos hacer - teniendo en cuenta a Jameson- de que el thriller inglés — siguiendo la tradición europea de, por lo menos, dos siglos — ha separado la esfera poético libidinal de la esfera económico política (manteniendo a Freud y a Marx separados) mientras que el relato latinoamericano, desde su tradición romántica, encapsula la cuestión política en el ámbito afectivo. Es decir, si James Bond (quien tiene prohibido involucrarse amorosamente, por lo menos antes del reciente remake de Casino Royal) se ve liberado de la naturaleza pasional para realizar su "misión”, en el caso de Maldonado ocurre lo contrario: la vinculación afectiva con las víctimas del crimen dirige su acción en forma compulsiva, desestabilizándolo, vulnerándolo, sobreenergizándolo, haciéndolo menos dueño de sus actos y haciendo valer más la pasión que la razón en su actuar, motivo adicional para enmarcar La cabeza de la hidra en el relato posmoderno. La asociación con James Bond va más allá, pues su jefe es TTM, posible alusión (entre otras) a "M", "la jefe de James Bond”. El jefe de Maldonado no es mujer, pero actúa como mujer; es decir, movido por una pasión afectiva antigua que lo liga a Maldonado desde sus tiempos de estudios en Columbia University, cuando compartían el cuarto, el lecho y la amistad. La elegancia, la clase, la distinción y la inteligencia de TTM no permiten que su atracción por Félix se llegue a manifestar como un incontrolado deseo de tipo homosexual, sabedor como es de la heterosexualidad de su amigo. Sin posibilidades de poseerlo sexualmente, planifica una forma sublimada pero, quizás, más perversa para adueñarse de su destino, como es gestar un proyecto en el que Maldonado se convierte en espía al servicio de los verdaderos intereses mexicanos, en contra de los que quieren traficar con su petróleo. TTM convierte a Félix en un muñeco, en un juguete usado cruelmente; todo lo contrario de James Bond, verdadero señor y sujeto de sus acciones. En este sentido, Burgess y Durán tienen razón al clasificar el texto de Fuentes como una "intentional parody of Ian Fleming”, "parodia intencional de Ian Fleming” (Durán, 1980:184).

No obstante, sostener que Maldonado es una copia tercermundista del intocable espía inglés resulta demasiado simple y, también, lo es situarlo simplemente al nivel de la parodia, restándole el carácter dramático de su situación en el mundo, un mundo que demuestra su cara más cruel y pragmática en varios niveles, sobre todo en lo referente a los mecanismos con 


\section{Carlos Fuentes y su incursión en la narrativa policial}

que operan los poderes fácticos en la destrucción de los ideales, en el aniquilamiento de los proyectos verdaderamente generosos como el de Sara, la única que - junto a Jamil — intenta una propuesta nueva para Palestina; propuesta marginal, inocente, heroica, destinada a sucumbir en un tiempo cuando ya no hay lugar para el sacrificio y el heroísmo. Maldonado asiste a este espectáculo siendo llevado por una máquina que le hace perder el nombre, el rostro, la personalidad, la identidad, sin saber siquiera qué procesos y decisiones lo van llevando hacia caminos no escogidos. Saber que algo extraño está ocurriendo con él, saber que otros saben más sobre él que él mismo, recibir advertencias sobre peligros que desconoce, etc., lo convierten más en un personaje kafkiano, desconocedor de su "proceso", que en un James Bond. Y, en esa medida, su suerte asume también las características de Felipe Montero, personaje de Aura (1962) quien, en palabras de Daniela Aspeé, "es una creación que ha surgido a partir de una necesidad" (2005) y que es llevado a un mundo ajeno al que conocía, marcado por la vacilación y la ambigüedad, mundo que se sustrae totalmente a las leyes positivas que normaban su concepción histórica de la realidad. Según Durán, “(Maldonado) [n]ot only is the protagonist devoid of gadgets, but he usually appears also devoid of understanding and even of basic intelligence. He is the hapless tool of the powers...”, "(Maldonado) no sólo es el protagonista desprovisto de recursos, sino que, por lo general, aparece también desprovisto de comprensión e incluso de una inteligencia básica. Es la infeliz herramienta de los poderes...” (1980:184).

En un nivel todavía más profundo, es necesario mencionar las múltiples relaciones textuales que explican la relación entre Félix Maldonado y el triple agente, TTM, jefe de la pequeña y mínima organización de espionaje para la que trabaja Félix. En primer lugar, forman una pareja literaria que recoge las tradiciones relacionadas con pares de personajes que representan —en sus múltiples relaciones de asociación, de disparidad y de complementación- la materialización clásica de las dos caras de una moneda. Mientras estudian en Columbia University, son Cástor y Pólux; la unidad que ostentaban era la razón de que sus amigos los llamaran así. Viven juntos, comparten el departamento, las aficiones (teatro y cine) la mesa de trabajo; viven como gemelos. La unidad sólo comienza a resquebrajarse la mañana cuando Félix cuenta a su amigo que ha hecho perder la virginidad a Mary en el mismo sofácama donde ellos dormían cada noche. En segundo lugar, ambos remiten al drama shakesperiano El mercader de Venecia: uno es Antonio, el rico mercader que ayuda a su amigo Basanio, por quien siente una cierta atracción; el otro es Basanio. La relación textual entre los personajes de la novela de Fuentes y el drama de Shakespeare orienta la interpretación de la relación afectiva que surge entre TTM y Félix, conducida por el sino trágico del amor 


\section{Jaime Alberto Galgani}

del primero hacia el segundo, sin que existiese posibilidad alguna de que éste, primero lo sospechase y, segundo, lo correspondiese. TTM desea poseer a Félix, pero éste, siendo heterosexual —además de ingenuo por caráctermira en otros sentidos. TTM anhela sublimar la realización de su deseo por la vía de un matrimonio de Félix con su hermana Angélica, la cual se relaciona intertextualmente con Ofelia de Hamlet (su muerte trágica es la señal de dicha relación). Puesto que TTM no puede poseer el cuerpo de Félix por ninguna vía, planifica toda una estrategia para controlar su vida, sus pasos, sus decisiones, incluso su identidad. En cierto modo, intenta poseer su alma, cuestión que le asigna un matiz fáustico a la novela y, como no logra que Félix lo ame, desea que por lo menos lo tema (237). Finalmente, el primero de los seudónimos de TTM, Timón de Atenas, es una alusión a la tragedia homónima de Shakespeare. Timón es aquel personaje en cuya bolsa "reina el más profundo infierno" (Timón de Atenas, iii, 4-15) porque "[h]ay algo que el poderoso Timón no pudo comprar. Un corazón” (236), cita que reafirma lo dicho recientemente.

TTM es un hombre rico y poderoso y jamás nos es accesible por medio de su nombre verdadero, se esconde tras su triple nominación de triple agente; habla de sí pero jamás se saca su máscara frente al lector. Como narrador, tiene el poder de dosificar la información que contiene y que va revelando, en dosis similares, tanto a Félix como al que lee. Félix, finalmente, lo sabe todo; el lector, casi todo, pues siempre el nombre verdadero de TTM permanece oculto. De alguna manera, es una alegoría de las máscaras mexicanas de Octavio Paz, pues nunca termina de "rajarse", abrirse, comprometerse y, ante Félix, sólo lo hace en momentos en que cuenta todo lo que había hecho con él y este lo insulta con palabras shakesperianas: "[t]hy mother's of my generation”, es decir, “Tu madre es de mi generación” (237), insulto a la madre que equivale a las peores ofensas mexicanas. Sólo en ese momento se destempla y pierde el control. No así ante el lector, lo cual revela la permanente superioridad del narrador que, en la semi-opacidad de sus revelaciones, juega con quien ha recorrido más de doscientos páginas tratando de ordenar el artificioso puzzle que le ha sido propuesto. De algún modo, TTM es Shakespeare, el dramaturgo, el gestor de una tragedia; Félix es el personaje (o el actor) con quien juguetea el experto "titiritero" (241); nosotros somos los espectadores. Félix Maldonado, al contrario de TTM, aparece totalmente expuesto, "rajado", abierto. Con él trajinan todos; de él se sabe todo; a él lo ningunean, lo llevan de un lado a otro, lo adormecen, lo hacen pasar por muerto, le cambian nombre, le cambian rostro; su sujeción a los caprichos del triple agente es también una alegoría, pues representa la endémica dependencia de las clases trabajadoras o definitivamente pobres a las decisiones unilaterales de la oligarquía mexicana, que siempre es la que 


\section{Carlos Fuentes y su incursión en la narrativa policial}

escribe el guión o el texto del drama que deben vivir los demás. TTM y Félix constituyen, juntos, la alegoría de un romance nacional que jamás se realiza, pues el poderoso Timón de Atenas (y la clase que él representa) puede comprarlo todo, menos un corazón.

Gloria Durán postula que Trevor/Mann (ella no menciona su tercer nombre, Timón) "represent the cool, logical brain who dominates his passionate antagonists through his cultivated aloofness", "representa el cerebro frío y lógico que domina a sus apasionados antagonistas con una trabajada (cultivada) actitud distante" (190) y lo considera como la contraparte de Herr Urs, en Cambio de piel (1967) personaje que, por sus pretensiones de poder y de omnipotencia, puede, a su vez, relacionarse con Otto Dietrich zur Linde, personaje de "Deutsches Requiem” (El Aleph, 1949) de Jorge Luis Borges. La asociación con Herr Urs permite establecer un cierto contacto con las pretensiones fáusticas del agente/narrador, puesto que Herr Urs es el artista enano que fabrica muñecos andróginos, que tiene la aspiración de ser Dios, que resucita como un títere y que señala un mundo siniestro con su arte, representando el mundo demoníaco y frustrado del artista, ${ }^{3}$ mientras que el personaje de La cabeza de la hidra es, también, el artista desfigurado ${ }^{4}$ que genera - como un dios - un mundo artificioso y reducido al servicio de su oscura pasión controlada: el deseo de poseer un alma. Gloria Durán también asocia a Trevor/Mann con Felipe Montero, quien "controls his own passions, all in the interest of a higher cause", "controla su propia pasión en beneficio de una causa superior" (190) y, como Felipe, es representado como un devoto católico, entendiendo su catolicismo como una necesidad que emana de una ausencia de pasión que solo puede ser superada por la Gracia: “-Soy católico, Félix. Sé que cuando se carece de pasión, la gracia fortuita puede salvarnos de su ausencia” (236).

Sin embargo, la frialdad de TTM es la apariencia de la frustración, no la falta de pasión y de deseo. Al contrario, el ser más apasionado de todos es él; pero, al mismo tiempo, es el más aquejado por el repliegue de sus temores, de sus desdichas, de sus fijaciones, de sus obsesiones. Incapaz del riesgo en su juventud, no se atreve a pronunciar su deseo ante el objeto mismo que lo provoca, ni de asumir racionalmente que nunca le pertenecerá. Su monstruosidad reside no en el deseo mismo, sino en la irracionalidad con que maneja su afecto. Antes de hablar, antes de reorientar sus deseos, prefiere

\footnotetext{
${ }^{3}$ Cfr. Zsuzsanna Csikós: "La influencia de J. L. Borges en Cambio de piel de Carlos Fuentes: Un ejemplo de intertextualidad. (Deutsches Requiem)”. Actahispanica, Acta Universitatis Szegediensis. Tomus V. Hungaria Szeged (2000):39-47.

${ }^{4}$ No por su condición homosexual, entiéndase, sino por la problematización que hace de sus afectos, por su obsesión dramática, por la obstinada perseverancia en un crimen por el cual es capaz de sacrificar, incluso, la vida de su hermana.
} 


\section{Jaime Alberto Galgani}

refugiarse en la religión y en la maquinación manipuladora que organiza años más tarde. Sin embargo, esta estrategia también fracasa. Cuando por fin Maldonado comprende todo lo que su amigo había hecho y las motivaciones de su actuación, TTM ve desarticuladas todas sus defensas y responde con la reacción más visceral de todas, aquella que desmorona la imagen del frío superespía internacional

[m]i estupefacción duró un minuto; me lancé sobre Félix, insultado, con rabia, herido por cuanto insinuaba, despojado de mis justificaciones perfectamente calibradas, pensadas, fraseadas; me arrebató la pistola de la mano pero antes yo había sido desnudado moralmente por este hombre... (237).

$Y$, en ese momento, en una escena de claras reminiscencias griegas, TTM puede tener a Félix en sus brazos, combatiendo juntos en un abrazo de amor-odio

[...] mi hermano, mi enemigo, al que finalmente poseía en un abrazo de odio, una lucha en la que nuestros cuerpos, que nunca se tocaron en la cama convertible del apartamento en Nueva York, se trenzaron ahora con rabia, rabia sólo mía, impotente, derrotada de antemano porque la cercanía sudorosa, tensa, apasionada del cuerpo de Félix, su mano con la pistola bajo mi axila, su brazo rechazando la impulsión de mi cintura, su pierna clavada entre mis testículos, no era sino el rechazo de un cuerpo que no deseaba el mío, despreciaba todas mis pasiones y había descubierto la más secreta de ellas, me convertía en un objeto animado pero inerte porque Félix se defendía de mi agresión física fríamente, como quien se defiende de un mosquito nocturno, sin importarle mi agresión pasional y al mismo tiempo queriéndome como siempre, como su viejo amigo, porque su imaginación tenía memoria y carecía de dolor y yo quería que me amara pero quería más que me temiera (237).

TTM en brazos de Félix se convierte en un "objeto inanimado pero inerte", similar al títere en que se convierte Herr Urs. Y esto sucede en el momento de la verdad, el momento cuando la pasión muestra su verdadero rostro, el instante en que los resortes racionales han sido rotos. La hidra, entonces, demuestra que tiene muchas cabezas. Una es la batalla políticomafiosa por traficar con el petróleo de México; otra es "la pasión”, quizás la cabeza más poderosa, la que nunca se puede hacer desaparecer, la que se manifiesta en la actuación de todos los personajes

-Ah, la pasión vuelve a levantar su espantosa cabeza de hidra (dice TTM a Maldonado). Corta una y renacerán miles, ¿Verdad? Llámala 
celos, insatisfacción, envida, desprecio, miedo, asco, vanidad, terror, escarba en los motivos secretos de todos los que hemos participado en esta comedia de errores, Félix, y ponle a la pasión el nombre que quieras. Nunca acertarás, porque detrás de cada nombre de la pasión hay una realidad oscura, política o personal, da igual, que nadie puede nombrar y que te impulsa a disfrazar de acción lícita o ilícita, también da igual, lo que sólo es pasión, hambre, padecimiento, deseo, un amor que se alimenta de su odio y un odio que se alimenta de su amor (235).

Es necesario, a este punto, recoger un comentario hecho anteriormente sobre la lectura alegórica de Fredric Jameson quien afirma controvertidamente que " $[\mathrm{t}]$ odos los textos del tercer mundo son necesariamente (...) alegóricos, y de un modo muy específico: deben leerse como (...) alegorías nacionales, incluso (o quizá debiera decir particularmente) cuando despliegan sus formas fuera de los mecanismos occidentales de representación predominantes, como la novela" (1986:69). A raíz de esto, se ha dicho, también, que "en el Tercer Mundo (o sea, nosotros) aún no ha ocurrido, como en el Primero, la separación de lo poético-libidinal y lo político-económico. En otras palabras: ya que en el Tercer Mundo Freud y Marx aún no se han divorciado, el destino de un personaje particular en una novela particular siempre refiere a la situación política y cultural de la nación” (2). Desentendiéndonos de los matices críticos que puede tener la teoría de Jameson (y más aún de su opinión sobre la subalternidad del intelectual tercermundista) es decir, acogiéndonos sólo a la vinculación que el personaje novelesco establece entre la esfera afectiva y la esfera política, parece ser que la suerte —al menos de este relato- corre por aguas que confirman el tratamiento que el crítico norteamericano da a la novela del Tercer Mundo al tipificarla como alegoría nacional. Ahora bien, se puede entender que, si en la alegoría de Jameson la cuestión amorosa está al servicio de la cuestión política, en La cabeza de la hidra es posible ver que esta última sirve a la primera, postulando que no son los intereses de nación los que norman la diégesis narrativa, sino, por el contrario, son las pulsiones afectivas las que dirigen el curso de las más intrincadas y oscuras tramas del orden social en todas sus vertientes. De este modo, la suerte del personaje detectivesco está involucrada, quizás, más allá de lo que se quisiera, con la fuerza del deseo, tal como lo hemos visto hasta ahora en Félix Maldonado y Timón/Trevor/Mann.

La contraparte femenina de Félix Maldonado está constituida por tres mujeres: la femme fatale (Mary), la figura de la Sabiduría (Sara Stein) y la "Gran Madre", que incluye a las otras dos (su esposa Ruth). Las tres son judías. Félix conoció a Sara en su época de estudiante y con ella establece una relación de afecto idealizado; es la mujer perfecta, el amor que nunca se 


\section{Jaime Alberto Galgani}

puede materializar. Conoció a Mary cuando estaba en la Universidad de Columbia y con ella tiene ciertos encuentros sexuales, pero nunca alcanza a plenificar todos los deseos de Félix. Ruth es la esposa, la que tiene perfecta conciencia del lugar que le corresponde en la vida de Félix

No soy tan inteligente como Sara ni tan guapa como Mary. (...) A Sara siempre la quisiste de lejos. Con Mary te acostabas. Pero para ti un amor puro y hasta intelectual o el puro sexo sin amor, no resuelve nada. Tú necesitas una mujer como yo, que te resuelva problemas prácticos, de tu carrera y tu vida social, y si las cosas diarias caminan bien, entonces puedes amar y coger a gusto con la misma mujer, a una sola mujer, que soy yo. Yo puedo ser tu ideal intocable por momentos, tu puta a veces, pero siempre la mujer que te tiene listo el desayuno, planchados los trajes, hechas las maletas, todo, las cenas para los jefes, todo. (...) Yo no era ni tu ideal puro como Sara ni un culo cachondo como Mary. Soy las dos a medias (42).

Según Gloria Durán, “(i)n Jungian terms we might say that the anima, incarnate here in the Great Mother, interprets the protagonit's splitting her up as a denial of normal maturation, as symptomatic o an unconscious desire by Félix to go back to the womb", "en términos junguianos, podríamos decir que el "anima”, encarnada aquí en la Gran Madre, interpreta la división del protagonista como una negación a la maduración normal, como un sintomático o inconsciente deseo de Félix por volver al vientre” (185).

Sin embargo, a pesar de esta sujeción materna que Ruth ejerce sobre Félix, él huye de ella y va al encuentro de Sara-Mary. Ruth parece desaparecer de escena y no tener nada que ver con la peripecia de la desaparición de Félix y de su muerte aparente. Hasta que la encontramos hacia el final, convertida en la Madre Terrible, relacionada con la muerte de Sara Stein y vestida de monja, revelando así el carácter "proteico” y macabro de su personalidad. De este modo, ella pasa de ser "(l)a Madre Tierra” a la vagina dentata (1980:185).

Evidentemente, también aquí las pulsiones sexuales juegan su rol protagónico como originantes de la tragedia y como causales primigenias de los crímenes; en este caso, el crimen de Sara, el que realmente interesa a Maldonado. Sexo y peligro están ahí indicando su vertiginosa vinculación y desencadenando la muerte del inocente, que es Sara, la única que representa los genuinos ideales heroicos de la honestidad, el coraje, el sacrificio de sí y que, al mismo tiempo, es inteligente y bella. Sara, junto a Jamil, el joven palestino, habían intentado vivir la utopía de la construcción de una patria compartida basados en el respeto por las culturas y el reconocimiento de la común condición humana, volviendo la espalda a los antiguos prejuicios de 


\section{Carlos Fuentes y su incursión en la narrativa policial}

raza, a los intereses internacionales egoístas y a la dinámica histórica que había convertido a Israel en el verdugo de Palestina, reproduciendo con los más débiles el tratamiento que ellos habían recibido por parte de la Alemania nazi.

Para entender mejor el rol de estas mujeres judías que enredan y confunden a Félix, es necesario acudir a una de las tradiciones de la formación del Antiguo Testamento y que, sin duda, tiene mucha relación con la general visión histórica del pueblo judío con respecto a la mujer. En efecto, la exégesis bíblica ha llegado a determinar que las fuentes literarias que generaron gran parte de los textos más importantes del Antiguo Testamento son las llamadas tradición Yavista, Eloísta y Sacerdotal. Esta última está presente en los textos vinculados al culto y a la práctica sacerdotal; la Eloísta se relaciona con los textos que colocan a Dios (Eloim) en su justo y lejano lugar sagrado. La tradición Yavista (llamada así por nombrar a Dios como Yavé) es la creadora (ya sea por obra de un autor individual o colectivo) de los textos relacionados con la constitución de la Monarquía de Israel y de su decadencia, generada por el sedentarismo, la incorporación de nuevos dioses, la corrupción de la corte y los vicios generados en todo proceso de institucionalización. El Yavista observa que, en la historia de los grandes errores de la Monarquía, siempre hay una mujer al inicio de la cadena que genera el "pecado". Así, por ejemplo, Betsabé tentando a David; las múltiples mujeres de Salomón adorando sus ídolos en el Templo; Atalía - la esposa de Joram - favoreciendo el culto a Baal y haciendo asesinar a toda la familia de su esposo; Jezabel —la esposa del rey Ajab- acusando falsamente al humilde Nabot y matando a sus hijos para que el rey pudiera tomar posesión de su viña. Todas estas observaciones contribuyeron a que el relato del Pecado Original (Gen 3) escrito por el Yavista, pusiera en muy mal lugar a la mujer, asignándole el lugar de la tentación. Al hombre (Adán) ciertamente no lo deja mejor, pues aparece como un pusilánime incapaz de reaccionar a la propuesta de Eva. Hasta aquí esta lectura, que postula el drama del paraíso a través de una meditación etiológica (efectuada por el autor Yavista) que buscaba las causas de la condición actual de la humanidad, contemplándola dentro de los esquemas de la historia de la salvación. ${ }^{5}$

Ahora bien, si se atiende a esta novela de Carlos Fuentes y no se toma por accidente la presencia del judaísmo en ella, se puede advertir una crítica similar a la que hace el Yavista en la época de la primera sedentarización del pueblo de Israel (hacia el año 1000 a. C.). Es decir, tres mil años después, cuando Israel tiene la oportunidad de una nueva sedentarización (la ocupación

\footnotetext{
${ }^{5}$ Para información sobre las tradiciones en la formación bíblica, ver diversos manuales. En particular, Xavier León-Dufour. Diccionario de teología bíblica. Herder, 2009.
} 


\section{Jaime Alberto Galgani}

de la tierra palestina tras la Segunda Guerra Mundial) sigue cometiendo los mismos crímenes de entonces; opera con la misma dinámica de la ocupación con que actuaron los antiguos israelitas al quitar su tierra a los cananeos, sigue aliándose con potencias extranjeras y prostituyéndose ${ }^{6}$ con ellas, es decir, negociando en beneficio propio y traicionando sus antiguos principios. Y, a nivel de tipificación cultural, la mujer sigue siendo la trampa que confunde a los hombres ${ }^{7}$ y se aprovecha de su debilidad para hacerlos sucumbir. Sara se salva de esta categoría solo a nivel de excepción, así como las buenas y escasas mujeres del pueblo de Israel consignadas por el Antiguo Testamento (Deborah, Ester, Judit).

La cabeza de la hidra, entonces, en medio de un relato policial, traza las líneas de un texto político que revisa críticamente la situación de la historia internacional de los años setenta. En el balance, árabes, norteamericanos y mexicanos aparecen unidos en la misma contienda de intereses y de valores corruptos. Pero son los judíos quienes aparecen particularmente corruptos y perversos. S. R. Wilson, en su reseña a la novela (1979), señala

Every Jew in the novel is a spy for Israel. Every Jew is a Mexican national and an Israeli agent; every jew is willing to sell land and information about Mexico to further the domination and control of the New York-Tel Aviv link... Jewish women abound in the novel; they all betray. Sara Klein... is unblemished because she falls in love with a young Palestinian when she is abruptly murdered by Israeli agents. The only good Jew, therefore, is the one who concedes historical and territorial rights of the Palestinian people in the Middle East. The others are grotesque caricatures of provocateurs, exploiters, drug-dealers, and whores; all closely linked to Zionism, the Irgun, and Israeli detention centers (citado por Durán, 1980:188). ${ }^{8}$

\footnotetext{
${ }^{6}$ El término "prostitución” es muy usado en el Antiguo Testamento con el fin de significar la fácil entrega de los israelitas a los dioses extranjeros y a las culturas que representaban.

7 "all the good and evil which is done in the world can be said without equivocation to be caused by women" (todo el bien y mal hecho en el mundo, se puede decir, sin equivocación, que es causado por mujeres). Luis Vives, citado por Durán 1980:194.

8 "Cada judío en la novela es un espía para Israel. Cada judío es un mexicano y (al mismo tiempo) un agente israelí; cada judío está dispuesto a vender tierra e información sobre México para mantener la dominación y control del eje New York-Tel Aviv... mujeres judías abundan en la novela; todas ellas traicionan. Sara Klein... es impecable (como excepción) porque ella se enamora de un joven palestino y es bruscamente asesinada por agentes israelíes. El único judío bueno, por lo tanto, es el que reconoce los derechos históricos y territoriales de los palestinos en el Oriente Medio. Los demás son las caricaturas de lo grotesco de los provocateurs, explotadores, traficantes de droga, y putas; todo estrechamente vinculado al Sionismo, el Irgun, y los centros de detención israelíes”.
} 


\section{Carlos Fuentes y su incursión en la narrativa policial}

El lugar de Félix Maldonado en medio de ese mundo “judío” es el de un converso para quien la conversión no ha revestido más que cierta formalidad y que, por el contrario, en todo momento lo ha puesto en una situación peligrosa (no olvidar que precisamente se pensaba utilizarlo, por su aparente condición de judío, para hacerlo figurar como protagonista de un atentado al Presidente). Esto se suma a que jamás podría haber sido un judío verdadero, por lo menos uno que - para serlo - tuviera que traicionar su condición mexicana y la integridad de una de las instituciones más fundamentales: la propiedad mexicana del petróleo. Maldonado se sentía profundamente vinculado, por influencia paterna, a dicha institución y decía haber sido concebido justo el 18 de marzo de 1938, fecha cuando Cárdenas decretó la nacionalización del petróleo. De esta razón se valió su amigo para invitarlo a participar en la organización espía que había fundado. Y, por igual razón, también es comprensible que Ruth le hubiera dicho, cuando se encontraron, por última vez: “-Nunca te convertiste en serio ¿Verdad?” (271).

En este punto es posible comprender cuáles son las dos pasiones que aprisionan a Félix Maldonado restándole su propia libertad para actuar. Por un lado, está Timón/Trevor/Mann y, por otro, las tres mujeres judías. Obsérvese

la coincidencia numérica: tres mujeres y un hombre que es tres, a la vez. Y el mismo Félix reúne en sí múltiples existencias: es Maldonado, es Velásquez. En realidad, el monstruo es policéfalo y los demonios son legión. De la multiplicidad de demonios se nutre la vigencia del mal.

\section{CONCLUSIONES}

El episodio del anillo deseado de la novela y su contención en la capilla de la casa de Coyoacán nos remontan a La invención de Morel (1940) de Adolfo Bioy Casares. Morel, el protagonista, crea una prodigiosa máquina que copia y emite no sólo la forma y el sonido, sino el volumen, el tacto, el olor y todo lo que hace a un objeto tener la apariencia de real. También nos conecta con el cuento "El Aleph" (1949) de J. L. Borges, en donde el personaje "Borges" desciende al sótano de la casa de Carlos Argentino Danieri y le es concedido observar ese objeto maravilloso que permite contemplar el "inconcebible universo". Así también Maldonado es llevado por TTM a la capilla donde le es revelado el secreto del anillo que contiene la información deseada gracias a la técnica del holograma. La entrada a la cripta secreta es activada tocando el lomo de una edición de Timón de Atenas, de Shakespeare. El holograma es visible gracias a un rayo láser que sale desde el ojo izquierdo de la imagen de la Virgen de Guadalupe, es decir, toda una representación de las más diversas tradiciones literarias apropiadas, iluminadas, por el más significativo de los símbolos mexicanos. Por otro lado, 


\section{Jaime Alberto Galgani}

el anillo nos comunica con la tradición de Orlando el furioso: "el anillo que el padre da a Angélica tiene la virtud de volver invisible. El siervo Brunello, mandado por el rey Agramante, roba el anillo y consigue un reino". ${ }^{9}$ Así, pues, el anillo de La cabeza de la hidra, si bien no tiene la capacidad de volver invisible, sí hace invisible la información que contiene y aquel que pueda conseguirlo adquirirá el poder de alcanzar un reino, en este caso, el poderoso y deseado reino negro que contiene una "riqueza superior a todo el oro de Moctezuma” (282). En Bomarzo (1962) de Manuel Mujica Láinez, el anillo que Benvenuto Cellini regala al joven duque Pier Francesco Orsini es el signo de una nueva elección y la marca de una nueva estirpe, aquella que lo releva de las pesadas cargas heredadas por la trágica genealogía de su familia romana; el duque ya no servirá a las armas, sino al arte y, por ese camino, alcanzará la inmortalidad que no alcanzaron sus sanguinarios antepasados. El anillo que guarda TTM en esa cripta secreta, en esa capilla-biblioteca, en esa cavidad que evoca el sótano de Borges, el infierno de Dante y el descenso de Virgilio a las regiones inferiores, mientras permanezca escondido en la casa de Coyoacán, no será sino un inocuo objeto cerrado, un críptico venero de información, un ambiguo artefacto que lo mismo puede servir para la ostentación artística como para el crimen.

Por el camino de la pesquisa policial, Fuentes nos ha llevado a la literatura. Su novela es, sin duda, el centón literario que agrupa innumerables textos y cita múltiples tradiciones. Más allá de su primer intento —el de crear un James Bond del subdesarrollo - ha generado una máquina textual de variados alcances. Su novela policial es, al mismo tiempo, una biblioteca.

\section{Universidad Católica Silva Henríquez* Departamento de Humanidades General Jofré 462, Santiago (Chile) \\ jgalganim@ucsh.cl}

${ }^{9}$ Diana García Simón: “El Renacimiento como tema en Bomarzo de Manuel Mujica Láinez”, en Espéculo. Revista de estudios literarios. Universidad Complutense de Madrid. 2002. En internet:

http://www.ucm.es/info/especulo/numero21/bomarzo1.html. 
Carlos Fuentes y su incursión en la narrativa policial

\section{BIBLIOGRAFÍA}

AGUILAR CAMÍN, Héctor. "La muerte de Artemio Cruz. Carlos Fuentes y la novela-tumba de la Revolución mexicana”, en El Mercurio, 17 de junio de 2007. Revisado, con fecha 9 de marzo de 2008, en:

El Mercurio / Chile / CHILE/

http://diario.elmercurio.com/2007/06/17/al_revista_de_libros/_portada/ noticias.

ÁLVAREZ, Ignacio. "Todos contra Jameson: los alcances de la alegoría nacional y su valor para la lectura de dos novelas chilenas recientes”. Pontificia Universidad Católica. Artículo no publicado.

ASPEÉ, Daniela. "Aura de Carlos Fuentes, un poema a la desesperada necesidad erótica”, en Espéculo. Revista de Estudios Literarios. Universidad Complutense de Madrid. 2005. Versión electrónica: http://www.ucm.es/info/especulo/numero30/auracf.html

BURGESS, Anthony. "The Hydra Head". New York Times: Book Review, January (1979):11.

CSIKÓS, Zsuzsanna. La influencia de J. L. Borges en Cambio de piel de Carlos Fuentes: Un ejemplo de intertextualidad. "Deutsches Requiem”. Actahispanica, Acta Universitatis Szegediensis. Tomus V. Hungaria: Szeged. (2000):39-47.

DURÁN, Gloria. The Archetypes of Carlos Fuentes. Hamden, Connecticut: Archon Book, 1980.

FUENTES, Carlos. "Carlos Fuentes, El diplomático”. Autobiografía escrita en tercera persona”. En:

http://www.mexicodiplomatico.org/aportadiplom/carlos_fuentes.pdf.

Revisado el 28 de julio de 2009.

------- La cabeza de la hidra. Ciudad de México: Joaquín Mortiz, S.A. 1985 (1978).

JAMESON, Fredric. "Third-World Literature in the Era of Multinational Capitalism”, en Social Texts 15 (Fall 1986):65-88. 